\title{
Avaliação Assistida de Habilidades Cognitivas em Crianças com Deficiência Visual e com Dificuldades de Aprendizagem
}

\author{
Cecilia Guarnieri Batista ${ }^{1}$ \\ Sylvia da Silveira Nunes ${ }^{2}$ \\ Universidade Estadual de Campinas \\ Letícia Enya Horino \\ Pontifícia Universidade Católica de Campinas
}

\begin{abstract}
Resumo
O presente estudo visa a discutir uma proposta de avaliação do "nível de desenvolvimento potencial”, conforme a concepção de Vygotsky, em crianças com deficiência visual (baixa visão ou cegueira) e dificuldades de aprendizagem. São relatados 2 estudos, em que a avaliação constou de aplicação do teste WISC verbal, avaliação do desempenho escolar em grupo e avaliação assistida individual, sendo selecionadas para análise as crianças com baixos valores de QI. No segundo estudo, o procedimento foi acrescido da observação de “espertezas", ou seja, de atuações que indicam capacidades cognitivas, fora da situação formal de avaliação. Os resultados indicaram evidências de aquisições na situação de avaliação assistida e de competências cognitivas variadas na análise das "espertezas". A discussão sobre modalidades de avaliação indicou possíveis fontes de dificuldade na obtenção de resultados indicadores do correto "nível de desenvolvimento potencial” em crianças com dificuldades de aprendizagem.

Palavras-chave: Avaliação assistida; crianças com dificuldades de aprendizagem; desenvolvimento e deficiência visual; desenvolvimento e dificuldades de aprendizagem.
\end{abstract}

\section{Assisted Assessment of Cognitive Abilities in Children with Visual Impairment and Learning Difficulties}

\begin{abstract}
This investigation aims at discussing a procedure of assessment of the "potential developmental level", according to the Vygostky's conception, in children with visual impairment (low vision or blindness) and with learning difficulties. In the 2 studies that are reported, the assessment procedure consisted of Verbal WISC administration, group assessment of school abilities and individual assisted assessment. The analysis was focused on the children with the lower IQ values. In the second study, the procedure also comprised the search for episodes of "smartness", indicating cognitive abilities, out of the formal assessment procedure. The discussion about modalities of assessment indicated possible sources of difficulty for the search of a reliable "potential developmental level" in children with learning difficulties.

Keywords: Assisted assessment; children with learning difficulties; child development and visual impairment; child development and learning difficulties.
\end{abstract}

O presente trabalho é fruto de uma preocupação com a avaliação das crianças participantes de um projeto integrado de pesquisa e intervenção, destinado a crianças com diagnóstico de deficiência visual, que vem sendo desenvolvido pela primeira autora desde 1995, em um serviço universitário para atenção a pessoas com deficiência.

Deficiência visual é entendida, no presente trabalho, como incluindo cegueira e baixa visão. De acordo com Colenbrander (1999), consideram-se como baixa visão os casos em que a acuidade visual varia de 0,25 a 0,02 e/ou em que o campo visual é inferior a $30^{\circ}$. (Na mesma classificação, a acuidade normal varia de 0,8 a 1,6 e o campo visual normal assume valores em torno de $60^{\circ}$.)

\footnotetext{
${ }^{1}$ Endereço para correspondência: Cepre- FCM- UNICAMP. Rua Tessália V. Camargo, 126 CP 6111, Barão Geraldo, 13084 971, Campinas, SP. Fone/ Fax: (19) 37888814 ${ }^{2}$ Agradecimentos ao Cepre-FCM-Unicamp, pelas facilidades para realização do presente estudo; ao FAEP-Unicamp, pela bolsa para a segunda autora e pelos equipamentos de vídeo e computação; à Fundap, pela bolsa de aprimoramento para a terceira autora; às aprimorandas Adriana H. Araújo e Cássia C. D. C. Botecchia, pela colaboração na coleta de dados do segundo estudo.
}

Outras alterações visuais incluem problemas de sensibilidade ao contraste, adaptação luz/escuro (ofuscamento), visão de cores e binocularidade. São considerados como "quase-cegueira" os casos de acuidade e campo inferiores aos citados, reservandose o termo "cegueira total" para ausência de percepção de luz e/ou de campo visual.

Uma definição mais voltada para a visão funcional é apresentada por Veitzman (2000), que apresenta o conceito elaborado em 1992 em Bangkok, a saber:

O portador de baixa visão é aquele que possui um comprometimento do seu funcionamento visual mesmo após tratamento ou correção de erros refracionais comuns e apresenta uma acuidade visual inferior a $6 / 18$ até percepção luminosa e um campo visual inferior a 10 graus do seu ponto de fixação, mas que utiliza ou é potencialmente capaz de utilizar a visão para o planejamento ou a execução de uma tarefa. (Veitzman, 2000, p. 3)

No caso do presente estudo, as crianças com baixa visão tinham acuidade inferior a 0,3 (ou 6/18). Eram consideradas 
cegas as crianças que, mesmo tendo alguma percepção de luz, utilizavam-se de recursos táteis para reconhecimento de objetos e de representações bidimensionais (desenhos, letras e números).

Uma das possibilidades de avaliação do desenvolvimento dessas crianças seria a aplicação de testes padronizados de inteligência. Entretanto, esses testes vêm sendo criticados por vários autores pela tendenciosidade que apresentam, na medida em que aspectos valorizados em sua construção trazem o viés de grupos social e culturalmente dominantes (Bock, Furtado \& Teixeira, 2001). Por outra ótica, são criticados, também, por não permitirem uma análise dos elementos sob avaliação. Nesse sentido, Coll e Onrubia (1996) apontam como problema do enfoque psicométrico sua incapacidade para analisar em que consistem realmente as aptidões medidas pelos testes e a explicação de suas conexões com a aprendizagem e o rendimento escolar. Os autores preconizam a perspectiva do processamento humano da informação, propondo a análise dos correlatos, conteúdos e componentes cognitivos das aptidões. Trata-se de uma abordagem mais analítica que a psicométrica, embora com pouca atenção aos aspectos sócio-culturais da constituição dessas aptidões.

Um outro foco para a questão é trazido por Vygotsky (1989), a partir da distinção entre desenvolvimento real e desenvolvimento potencial, com a noção de zona de desenvolvimento proximal. Esta é definida como:

a distância entre o nível de desenvolvimento real, que se costuma determinar através da solução independente de problemas, e o nível de desenvolvimento potencial, determinado através da solução de problemas sob a orientação de um adulto ou em colaboração com companheiros mais capazes. (p. 97)

Nessa perspectiva, os testes padronizados teriam como objetivo avaliar o nível de desenvolvimento real, o que poderia ser útil para certos fins, como, por exemplo, a seleção dos mais aptos para determinada tarefa. Para fins educacionais, entretanto, faz muito mais sentido a avaliação do nível de desenvolvimento potencial, centrando-se em tarefas e habilidades que o indivíduo já realiza com ajuda ou apoio, em situações favoráveis, e não em realizações independentes, presentes mesmo em situações adversas (como é o caso, por exemplo, de um exame de seleção). Além disso, com essa abordagem, o fenômeno é enfocado de modo mais abrangente do que o possibilitado pela análise de componentes cognitivos, pois o que se estuda são as interações constitutivas das habilidades observadas.

Essa é a idéia da avaliação assistida, conforme descrita na revisão de Linhares (1995), autora pioneira na adoção dessa modalidade de avaliação no Brasil. Em seus trabalhos (Linhares, 1998; Santa Maria \& Linhares, 1999), a autora vem adotando o método estruturado de avaliação, com intervenções de ajuda sistematizadas, incluindo fases sem e com assistência, ao invés de um método clínico, em que as intervenções de ajuda por parte do examinador são oferecidas livremente (Linhares, 1995). Um exemplo é o trabalho de Santa Maria e Linhares (1999), em que foram avaliadas crianças com queixa de dificuldade de aprendizagem escolar e classificadas como deficiente mental leve. A avaliação assistida foi realizada por meio de duas tarefas: 1) perguntas de busca de informação com exclusão de alternativas e 2) raciocínio analógico, com um delineamento com as seguintes fases: preliminar, inicial sem ajuda, assistência, manutenção e transferência. Os resultados permitiram a identificação de variações entre as crianças, $O$ que não foi propiciado pela aplicação do teste psicométrico, no qual as crianças apresentaram resultados relativamente homogêneos.

O procedimento de avaliação assistida foi utilizado para a avaliação do desenvolvimento cognitivo de crianças com diagnóstico de cegueira ou baixa visão por Enumo e Batista (2000). A exigência de materiais facilmente reconhecíveis por crianças cegas ou com baixa visão exigiu a adaptação ou criação de provas e a preparação das mesmas com material específico. Todas as provas foram aplicadas de acordo com o método estruturado de avaliação, segundo a distinção de Linhares (1995) entre método estruturado e método clínico. Os resultados indicaram, de modo geral, melhora no desempenho das crianças ao longo das provas assistidas. Mostraram que as diferenças em nível de habilidade não tinham relação com o tipo de deficiência visual, estando mais relacionadas à presença de problemas orgânicos adicionais, tais como a presença de síndromes e de alterações neurológicas. Confirmaram-se, assim, as postulações sobre as possibilidades de pleno desenvolvimento cognitivo do indivíduo cego (Batista \& Enumo, 2000). Entretanto, quando a análise foi centrada nas crianças que apresentaram as maiores alterações no desenvolvimento, alguns problemas foram detectados. Várias dessas crianças não mantinham a atenção pelo período necessário para aplicação de cada prova, com suas etapas de avaliação inicial (sem ajuda), ensino (com apresentação de vários tipos de ajuda) e avaliação final (sem ajuda). Mostravam sinais crescentes de impaciência e de não envolvimento nas tarefas propostas. Dessa forma, seu desempenho não era bom, e parecia não refletir todas as suas possibilidades de aprendizagem. Considerou-se que um dos problemas era o fato de que, quanto mais padronizadas as tarefas, maior a dificuldade de envolvimento dessas crianças.

O objetivo do presente estudo é apresentar e discutir uma proposta de avaliação centrada na obtenção de indícios de aprendizagem e desenvolvimento em crianças com baixo desempenho em procedimentos de avaliação sistemática e 
padronizada. Para tanto, serão descritas as propostas de avaliação adotadas nos 2 últimos anos com população semelhante à acima descrita (Estudo 1: 2001, Estudo 2: 2002). Nos dois estudos, a avaliação constou de aplicação de teste (WISC verbal), de algumas provas grupais de avaliação do desempenho escolar e de avaliação assistida individual (de acordo com o método clínico segundo distinção de Linhares, 1995). No Estudo 2, foi acrescentada, também, a observação incidental de ocorrência de "espertezas", ou seja, exemplos de situações em que a criança demonstrava capacidades cognitivas, fora da situação mais formalizada de avaliação.

\section{Método}

\section{Participantes \\ Estudo 1 (avaliação de 2001)}

Foram submetidas à avaliação todas as crianças participantes dos grupos do referido projeto em 2001. Serão apresentadas as crianças que freqüentaram a maior parte das sessões dos grupos, e que participaram do processo completo de avaliação. As crianças serão identificadas por nomes fictícios. A idade das crianças corresponde ao mês de agosto de 2001, quando se iniciaram as avaliações. Para caracterização da situação econômica das familias, foram consideradas as seguintes faixas de renda familiar: 1 - até 2 salários mínimos (SM); 2- de 3 a 10 SM; 3- acima de 10 SM.

As crianças do grupo Pré (faixa etária de 4 a 7 anos) eram as seguintes:

- Beatriz, com 4 anos e 11 meses, cega (retinoblastoma com 5 meses em um olho e com 3 anos no outro). Morava com a mãe e com avós maternos, tinha ingressado em préescola particular naquele ano, familia com renda familiar na faixa 3.

- Edith, com 6 anos e 9 meses, baixa visão profunda, problemas na córnea (ausência do reflexo de piscar), na musculatura oromastigatória (síndrome de Riley Day) e atraso no desenvolvimento neuropsicomotor. Morava com os pais eirmãos mais velhos, tinha ingressado em pré-escola pública no segundo semestre, renda familiar na faixa 2.

- Gilberto, com 4 anos e 4 meses, cegueira congênita, prematuridade (nasceu com 840 g), episódios repetidos de pneumonia e infecção urinária no primeiro ano de vida. Morava com a mãe, tios e avós maternos; não estava na escola, renda familiar na faixa 2.

— Talita, com 6 anos e 1 mês, cegueira congênita. Morava com a mãe, irmã e atual companheiro da mãe, cursava préescola pública há vários anos, renda familiar na faixa 2.

- Inácio, com 4 anos e 11 meses, baixa visão (moderada para perto, profunda para longe), corioretinite por toxoplasmose, prematuridade (1500g). Morava com a mãe viúva, irmã adolescente e sobrinho, estava na pré-escola pública, tinha começado a freqüentar o grupo em outubro de 2001, renda familiar na faixa 2.

As crianças do grupo Alfa I (matriculadas nas séries iniciais do ensino fundamental) eram as seguintes:

- Eduardo, com 7 anos e 4 meses, cegueira congênita, síndrome de Saethre-Chotzen (craniotomia aos 6 meses, microbraquicefalia). Morava com os pais e irmãos, cursava a $1^{a}$ série em escola pública, renda familiar na faixa 2 .

- Karina, com 11 anos e 3 meses, baixa visão severa, microcefalia, epilepsia, má-formação do SNC. Morava com os pais, cursava a $3^{\text {a }}$ série em uma escola particular com proposta inclusiva, renda familiar na faixa 3 .

- Osvaldo, com 9 anos e 11 meses, baixa visão moderada. Morava com os pais e irmãos, cursava a $2^{\mathrm{a}}$ série em escola pública, renda familiar na faixa 1.

Do grupo Alfa II, apenas uma criança participou do processo de avaliação completo:

— Lúcio, com 8 anos e 4 meses, baixa visão moderada, prematuridade (1750 g), episódios de convulsão sob controle. Morava com os pais, cursava $2^{\text {a }}$ série em escola particular, renda familiar na faixa 3 .

\section{Procedimento de Avaliação}

O procedimento de avaliação constou de um conjunto de provas padronizadas e assistidas. Iniciou-se em agosto, com as tarefas de desempenho escolar em grupo e aplicação do WISC.

1- Avaliação psicométrica: foi escolhido o teste WISC verbal, padronização realizada por Lemgruber e Paine (1981) na cidade do Rio de Janeiro, com predomínio de crianças de escolas públicas na amostra. Foi escolhido um teste verbal, para reduzir as diferenças de desempenho de crianças com diferentes graus de visão e de crianças cegas, que ocorreriam nos testes de execução.

2- Avaliação em grupo: constou das seguintes tarefas: a) Desempenho escolar: foram apresentadas, de modo previamente sistematizado, tarefas envolvendo desenho, identificação de cores, letras e palavras, escrita e contagem até 6 para as crianças do Grupo Pré, e tarefas envolvendo leitura, escrita, contagem e comparação de quantidades para as crianças do Grupo Alfa.

Todo o material utilizado era adaptado para crianças com deficiência visual. Para as crianças cegas, o desenho era realizado em papel comum, preso em uma prancheta revestida por tela plástica, de modo a fornecer retorno tátil dos traçados realizados. A identificação de letras era feita com alfabeto móvel (letras comuns emborrachadas), que era o material mais utilizado nas atividades dos grupos. Palavras eram apresentadas em cartões que continham a palavra em braile e em tinta, em tipos ampliados, com a primeira letra da palavra também em letra emborrachada. 
Para atividades de escrita, eram oferecidas várias opções, dependendo dos conhecimentos da criança: alfabeto móvel com letras comuns emborrachadas ou escrita braile (máquina ou alfabeto móvel). Para as crianças com baixa visão, eram oferecidos materiais escritos com tipos grandes e com bom contraste. Para desenho e escrita, eram disponibilizados papel, giz de cera, lápis comum e de cor e canetas ponta porosa. As contagens eram realizadas com cubos de madeira de cor vermelha $(2 \mathrm{~cm}$ de lado), ou com pares Proepre ${ }^{3}$, cujos círculos, pretos sobre fundo branco, tinham referência tátil (pingo de cola de madeira sobre o círculo). A tarefa de identificação de cores era realizada com cartões com borrões de tinta bem nítidas, e com pistas táteis variadas, correspondentes às cores.

b) Conversas temáticas: aproveitando o período de conversa inicial das sessões, foram propostos temas para conversa, um por sessão, envolvendo família, vinda para o projeto e escola da criança.

3-Avaliação individual assistida: foi aplicada a prova de contagem, para as crianças dos Grupos Alfa cujo desempenho no grupo não ficou claro, ou indicou pouco conhecimento.

Contagem: contar cubos até 9 , e contar novamente, com subtração sucessiva de 1 em 1 cubo.

\section{Procedimentos de Coleta de Dados e Análise de Dados}

O teste WISC foi aplicado de acordo com as instruções padronizadas, com o primeiro autor aplicando o teste e um estagiário de psicologia fazendo as anotações, para as crianças com idade a partir de 6 anos.

Os procedimentos de avaliação em grupo e individual foram filmados em vídeo. Foi feita a transcrição das atividades de classificação livre (em grupo e individual), conversa temática (em grupo) e contagem (individual). As demais atividades em grupo foram estudadas a partir de análise do vídeo, com base nas categorias apresentadas a seguir.

\section{Categorias de análise de desempenho escolar}

As tarefas relativas a desempenho escolar foram analisadas tendo em vista: o nível de desempenho da criança na tarefa (Ex: desenho reconhecível ou não, escrita independente de palavras ou início do traçado distinto do desenho, etc) e o grau de ajuda, orientação ou pistas recebidas. As categorias para análise foram, basicamente, as seguintes: AS (resposta correta sem interferência), AP (resposta correta após pistas), $\mathrm{C}$ (chute), ES (erro sem interferência), EP (erro após pistas), RO (resposta após orientação direta), NS (não resposta, sem interferência), NP (não resposta após pistas).

\footnotetext{
${ }^{3}$ Proepre é um programa de orientação piagetiana para educação infantil desenvolvido pela Prof ${ }^{a} \mathrm{Dr}^{\mathrm{a}}$ Orly Z. M. Assis. Inclui vários materiais, inclusive os cartões mencionados: pares de cartões, com círculos desenhados (1 a 6), em que se tem o cuidado de dispor em posições diferentes os conjuntos de mesma quantidade, de modo a evitar o reconhecimento pela configuração visual.
}

Para tarefas como desenho, leitura de palavras, escrita e contagem houve necessidade de acréscimo de algumas categorias, que serão apresentadas junto com os resultados relativos às mesmas.

\section{Categorias de análise de conversas temáticas}

Os diálogos relativos às conversas temáticas foram transcritos na íntegra. A seguir, enfocando-se cada criança, foi feito um resumo dos diálogos, e feita uma análise, que buscou responder perguntas relativas às seguintes categorias: 1- Fidelidade ao tema (Mantém-se no tema ou aborda outros temas? Quais? Ao falar sobre o tema, é abrangente ou episódico? Como?); 2- Qualidades da narrativa (é compreensível, no que se refere à articulação da fala? É coerente e contextualizada? É detalhada? Como? É realista ou fantasiosa?); 3- Influência do grupo (Inicia assuntos ou continua assuntos trazidos por colegas? Como?)

\section{Resultados}

Os resultados da aplicação do WISC verbal estão apresentados na Tabela 1 . Verifica-se que os totais variaram de 65 a 111, sendo os valores mais baixos os de Edith, com 67 e Karina, com 65.

Tabela 1

\begin{tabular}{clc} 
Valores de QI (WISC verbal), nas Crianças Participantes do Estudo 1 \\
\hline Grupo & Criança & $2^{\circ}$ sem. 2001 \\
\hline Pré & Beatriz & NI \\
& Edith & 67 \\
& Gilberto & NI \\
& Inácio & NI \\
& Talita & 111 (fev. 02) \\
Alfa I & Eduardo & 94 \\
& Karina & 65 \\
& Osvaldo & 91 \\
Alfa II & Lucio & 101
\end{tabular}

Nota: NI- não tinha a idade mínima para aplicação do WISC

Uma vez que, no presente estudo, se aborda a questão de como identificar possíveis competências cognitivas em crianças com dificuldades, os resultados das demais avaliações serão apresentados para as duas crianças que tiveram os resultados mais baixos no WISC: Edith e Karina.

\section{Resultados de Edith}

O procedimento de análise para os dados de Edith é apresentado em detalhe no Anexo A. Conforme se depreende da análise explicitada nesse Anexo, o desempenho escolar de Edith situou-se abaixo do esperado para a classe de pré. Indicou, entretanto, várias aquisições (reconhecimento do nome, início da identificação de letras). Durante as conversas temáticas, falou pouco, atendo-se a responder ao que era perguntado, e mostrou vários conhecimentos sobre situações da vida diária. 


\section{Resultados de Karina}

Em relação a seu desempenho escolar, os principais resultados foram os seguintes:

Quanto à leitura (tarefa: cartões, cada um com uma palavra, apresentados em rodízio no grupo), suas respostas foram categorizadas como Identificações Parciais (de letras nas palavras) ou como Reconhecimento após Pistas (RP). Seu desempenho foi assim sintetizado: Identificou algumas letras (A, O, I, E). A partir da apresentação oral do início de uma palavra, inferia qual era a palavra (Ex.: “ele"....”fante").

Quanto à escrita, seu desempenho foi categorizado como Traçado sem Interferência (TS). Síntese: Ao escrever seu nome, fez A e I reconhecíveis, e outros traços parecidos com letras. No pedido de escrita de outras palavras, fez algumas letras, não dizendo o que estava escrevendo.

Contagem: com pares Proepre, acertou contagens até 3 ; de 4 a 6, seus acertos não foram sistemáticos. Recitação de seqüência de contagem, em rodízio com os colegas: em geral, acertou na contagem em ordem crescente até 20 , recusou-se a participar da contagem decrescente (começando do 20). Quanto à tarefa de comparação de quantidades (Ex.: “O que tem mais: 16 ou 7?”), não acertou a duas questões, mesmo após explicações.

- Desempenho escolar - síntese: No que se refere ao desempenho escolar, avaliado em situação de grupo, verificouse que Karina tinha rudimentos de leitura (identificou algumas letras), de escrita (algumas letras reconhecíveis na escrita de seu nome), e contagem (acertos assistemáticos na correspondência até 6 e na recitação da seqüência até 20 ).

- Conversas temáticas: Em geral seus relatos foram considerados ricos, detalhados e apresentados de modo compreensível. Sempre trazia fatos novos, em geral pertinentes ao tema, poriniciativa própria (Ex.: ao falar de familia, deu detalhes sobre suas relações cotidianas com os avós, que moram perto).

- Avaliação assistida individual - contagem: $\mathrm{Na}$ tarefa de contar 9 cubos, inicialmente precisou de ajuda (erros na correspondência). Ao serem retirados os cubos um a um, refez a contagem a cada vez, acertando na maioria das vezes, e respondendo certo, sem contar, para 1 e 2 .

\section{Considerações sobre os resultados de Karina}

Karina demonstrou grandes dificuldades nas tarefas de desempenho escolar, e, na avaliação assistida individual, mostrou evidentes aquisições no momento na avaliação, após orientações. Por outro lado, seus relatos eram bastante ricos e completos, com desenvolvimento próprio a partir do que era perguntado.

\section{Participantes}

\section{Estudo 2}

Foram submetidas à avaliação assistida todas as crianças participantes dos grupos do projeto em 2002. Um total de 10 crianças participou de forma constante do projeto e da avaliação nesse ano.
As crianças do grupo Pré (faixa etária de 4 a 7 anos) eram as seguintes:

- Beatriz, Gilberto e Inácio, que já participaram do Estudo. Beatriz e Inácio continuavam na pré-escola, na classe correspondente a sua faixa etária, e Gilberto havia ingressado na escola. Os dados sobre idade serão relativos ao mês de agosto de 2002, quando as avaliações eram iniciadas.

- Gisela, com 6 anos e 2 meses, baixa visão profunda, calcificações cerebrais devido a infecção congênita. Morava com a mãe e irmã, e próxima de outros parentes, tinha freqüentado APAE quando pequena, tinha ingressado e saído de uma pré-escola no início de 2002, estava iniciando na instituição e em nova pré-escola em maio de 2002, familia com renda familiar na faixa 1.

— Nivaldo, com 6 anos e 2 meses, baixa visão profunda recente, devida a tumor cerebral benigno recentemente removido. Morava com os pais e irmãs, estudava em préescola particular há vários anos. Pais de nível universitário, faixa de renda 3 .

As crianças do grupo Alfa I (matriculadas nas séries iniciais do ensino fundamental) eram as seguintes:

- Lúcio e Talita, já participantes do Estudo 1. Lúcio estava matriculado na $3^{\mathrm{a}}$ série, e Talita, na $1^{\mathrm{a}}$ série.

- Daniel, com 9 anos e 10 meses, baixa visão profunda, hemiparesia do lado direito, episódios de convulsão sob controle. Morava com os pais, tinha freqüentado APAE, estava matriculado na $1^{a}$ série da escola regular, apresentava quadro de hiperatividade. Renda familiar na faixa 2.

- Do grupo Alfa II, participavam Edith e Karina, já participantes do Estudo 1. Edith tinha ingressado na $1^{a}$ série do ensino fundamental, e Karina estava matriculada na $4^{a}$ série da mesma escola, com proposta de atenção diferenciada para suas peculiaridades.

\section{Procedimento de Avaliação}

A avaliação foi semelhante à de 2001, diferindo nos seguintes aspectos:

Avaliação em grupo

Para os Grupos Alfa, na avaliação de desempenho escolarcontagem, não foi feita comparação entre quantidades e foi solicitada a identificação de numerais.

As conversas temáticas tiveram algumas alterações, consistindo em: férias, atividades prediletas, final de semana e escola (do que gosto e do que não gosto).

Avaliação individual

A aplicação individual enfocou tarefas nas quais a criança tivesse tido problemas e, ao mesmo tempo, demonstrado potencial de aprendizagem, sem definição prévia de tarefas por criança. Foi aplicada também para as crianças do Grupo Pré.

Nova modalidade de avaliação

Foi introduzida uma nova forma de avaliação, denominada de "busca de espertezas": ao longo das sessões, e também em outras situações (ex: lanche, sala de espera) buscou-se 
observar e anotar, sistematicamente, episódios em que as crianças, especialmente as que apresentavam mais dificuldades cognitivas, demonstravam capacidade intelectual em situações cotidianas e informais, fora das tarefas prescritas. Essas anotações foram realizadas por todos os que participavam das sessões (docente, aprimorandos e estagiários participantes) ao longo do segundo semestre de 2002.

\section{Procedimentos de Coleta e Análise de Dados}

Foram semelhantes aos do Estudo 1. A busca de "espertezas" processou-se como descrito acima, tendo as autoras do presente estudo a responsabilidade de coletar, sistematicamente, essas observações, a partir das anotações feitas pelos aprimorandos/ estagiários participantes da sessão.

\section{Resultados}

Os resultados da aplicação do WISC verbal são apresentados na Tabela 2.

Para as crianças já avaliadas no Estudo 1, observou-se pequeno aumento nos valores do QI, especialmente nos de Edith e Karina. Das crianças avaliadas pela primeira vez, foram observados valores baixos para Gisela, Inácio e Daniel.

À semelhança do que foi feito com os resultados do Estudo 1 , serão destacadas para análise as crianças que tiveram valores baixos no WISC, a saber: Gisela, Inácio, Daniel, Edith e Karina. Os resultados serão apresentados de modo mais sintético que no Estudo 1, uma vez que a metodologia utilizada para análise já foi demonstrada. Na Tabela 3, são apresentados de modo muito

Tabela 2

Valores de QI (WISC verbal) nas Crianças Participantes dos Estudos 1 e 2

\begin{tabular}{cccc}
\hline Grupo em 2002 & Criança & Estudo 1 & Estudo 2 \\
\hline Pré & Beatriz & NI & 116 \\
& Gisela & - & 67 \\
& Inácio & NI & 70 \\
& Nivaldo & - & 129 \\
\multirow{3}{*}{ Alfa I } & Daniel & - & 70 \\
& Lúcio & 101 & 105 \\
& Talita & 111 (fev. 02) & 115 \\
Alfa II & Edith & 67 & 74 \\
& Karina & 65 & 71
\end{tabular}

Nota: NI- não tinha a idade mínima para aplicação do WISC

Tabela 3

Sintese dos Resultados das Provas em Grupo, relativas a Desempenho Escolar

\begin{tabular}{|c|c|c|c|c|c|}
\hline crianças & cores & desenho & leitura & escrita & contagem \\
\hline $\begin{array}{l}\text { Gisela } \\
\text { (pré) }\end{array}$ & identificou & não reconhecível & $\begin{array}{l}\text { identificou letra } \\
\text { inicial de seu nome }\end{array}$ & $\begin{array}{l}\text {-não diferenciou desenho de } \\
\text { escrita }\end{array}$ & $\begin{array}{l}\text {-falou seqüência até } 7 \\
\text {-não fez }\end{array}$ \\
\hline Inácio & identificou & não avaliado & & $\begin{array}{l}\text {-traçados como rabiscos } \\
\text {-disse que seu nome começa } \\
\text { com G }\end{array}$ & $\begin{array}{l}\text { correspondências } \\
\text {-falou seqüência até } 7 \\
\text {-não fez }\end{array}$ \\
\hline (pré) & & & $\begin{array}{l}\text { não identificou } \\
\text { letras ou palavras }\end{array}$ & $\begin{array}{l}\text {-diferenciou desenho de } \\
\text { escrita } \\
\text {-traçados como bolinhas }\end{array}$ & $\begin{array}{l}\text { correspondências } \\
\text {-contagem de } 1 \text { e } 2 \\
\text { objetos }\end{array}$ \\
\hline $\begin{array}{l}\text { Daniel } \\
\text { (alfa I) }\end{array}$ & $\begin{array}{l}\text { não } \\
\text { identificou }\end{array}$ & não reconhecível & $\begin{array}{l}\text { não identificou } \\
\text { letras ou palavras }\end{array}$ & $\begin{array}{l}\text {-não diferenciou desenho de } \\
\text { escrita }\end{array}$ & $\begin{array}{l}\text {-não fez } \\
\text { correspondências }\end{array}$ \\
\hline $\begin{array}{l}\text { Edith } \\
\text { (alfa II) }\end{array}$ & $\begin{array}{l}\text { já identificava } \\
\text { no ano } \\
\text { anterior }\end{array}$ & $\begin{array}{l}\text { parcialmente } \\
\text { reconhecível }\end{array}$ & - & $\begin{array}{l}\text {-traçados parecidos com } \\
\text { letras ( } \mathrm{E} \text { invertido) }\end{array}$ & $\begin{array}{l}\text {-falou seqüência até } 4 \\
\text {-não fez } \\
\text { correspondências }\end{array}$ \\
\hline $\begin{array}{l}\text { Karina } \\
\text { (alfa II) }\end{array}$ & $\begin{array}{l}\text { já identificava } \\
\text { há vários anos }\end{array}$ & $\begin{array}{l}\text { parcialmente } \\
\text { reconhecível } \\
\text { (temas gerais } \\
\text { identificáveis) }\end{array}$ & $\begin{array}{l}\text { identificou algumas } \\
\text { letras e palavras } \\
\text { conhecidas }\end{array}$ & $\begin{array}{l}\text {-traçados com algumas letras } \\
\text { reconhecíveis }\end{array}$ & $\begin{array}{l}\text {-falou seqüência até } 6 \\
\text {-fez algumas } \\
\text { correspondências }\end{array}$ \\
\hline
\end{tabular}


sintético os resultados das provas em grupo, relativas a desempenho escolar, para as cinco crianças.

A análise da Tabela 3 mostra que se trata de crianças com grande defasagem no desempenho escolar, mais acentuada no caso das crianças mais velhas, Daniel e Karina. Os outros também apresentam dificuldades, podendo-se relevar, entretanto, as dificuldades de leitura e escrita das crianças pré-escolares, pois diferentes escolas trabalham essas habilidades em tempos diferentes.

Os resultados por criança serão apresentados de modo mais sintético que no Estudo 1, detalhando-se o novo item, referente à identificação de "espertezas".

\section{Resultados de Gisela}

- Desempenho escolar: Nomeou cores corretamente. Seu desenho não era reconhecível; não mostrou consistência quanto a temas anunciados em relação a traçados realizados. Identificou algumas letras, com mais constância para a letra G (letra inicial de seu nome real). Quanto à identificação de crachás, identificou o seu, dentre os dos colegas. Disse que seu nome começava com $G$, precisou de orientação direta para escrever com alfabeto móvel; no papel, fez traçados como rabiscos. Recitou a seqüência de contagem até 7; fez contagens sem atentar para os aspectos relevantes da tarefa (Ex.: examinar o material a ser contado).

- Conversas temáticas: Em geral, manteve-se no tema, baseando-se, muitas vezes, nos episódios que os colegas traziam. Suas frases eram um pouco truncadas, algumas vezes com perda da coerência.

- Avaliação assistida individual - contagem: Apresentou acertos e erros ao recitar seqüência numérica (até 10), sem regularidade. Precisou de orientação para fazer correspondências, acertando partes de seqüências de contagem de objetos. Passou a mostrar mais atenção à tarefa, que nas situações de avaliação em grupo.

— "Espertezas": Dentre os exemplos de demonstração de capacidade cognitiva de Gisela fora das situações de avaliação, são apresentados, a seguir, os mais significativos:

Quando o adulto coordenador estava ditando palavras para Nivaldo e falou "rinoceronte", Gisela falou "Quindim" (rinoceronte do sítio) e lembrou-se de outros personagens do Sítio do Pica-Pau Amarelo (história que ela ouviu em outro lugar, não nesse grupo do projeto).(12/08)

$\mathrm{Na}$ brincadeira no tapete, Gisela pegou o violão, dedilhou (sem tocar música) e cantou várias músicas conhecidas.(16/ 08)

$\mathrm{Na}$ brincadeira no tapete, Gisela brincou com a caixa de cozinha, serviu suco para as crianças e os adultos, brincou de passar a roupa das pessoas e secou o cabelo de todos com o secador.(19/08)

Na situação de identificação de crachás no início da sessão, Gisela mostrou dois " $\mathrm{A}$ " no crachá dela corretamente.(11/ 11)

Psicologia: Reflexão e Crítica, 2004, 17(3), pp.381-393
Ao ouvir uma história sobre galinha e seus pintinhos, falou: "Minha mãe não cria pintinhos, cria eu".(11/11)

Quando se estava perguntando sobre as crianças do grupo que haviam faltado, Gisela sempre se lembrava de Dimas, que há tempo não vinha aos atendimentos. (várias vezes, ao final do $2^{\circ}$ semestre).

\section{Considerações sobre os resultados de Gisela}

As avaliações mais formais de Gisela indicaram baixo desempenho, enquanto algumas capacidades de relato surgiram nas conversas temáticas. A avaliação assistida individual de contagem indicou algumas aquisições, com um início de correspondência. Por outro lado, a observação de seu desempenho, ao longo das situações mais informais das sessões, durante o segundo semestre, indicou a ocorrência de várias habilidades cognitivas, tais como lembrar-se de fatos ocorridos anteriormente, conhecer músicas, identificar letras, estabelecer relações (criar pintinhos, criar os filhos) e demonstrar conhecimentos variados do cotidiano em situação de brincadeira faz-de-conta.

Gisela tinha freqüentado APAE quando pequena. Em 2002, ingressou e foi desligada de uma pré-escola regular. Começou a ser atendida no projeto em maio e, pouco tempo depois, ingressou em outra pré-escola. Sua professora, em contato com a equipe do presente projeto, disse que estava preocupada, pois tinham informado que ela iria receber uma criança "cega e DM". Como Gisela não parava por muito tempo em cada atividade, e algumas vezes começava a gritar, a professora pensava que suas piores expectativas estavam se confirmando. Essa professora foi orientada no sentido de tentar promover habilidades de Gisela. Em poucos meses, a professora passou a relatar algumas aquisições de Gisela, o que, também, foi sendo observado no projeto.

\section{Resultados de Inácio}

Será feita a comparação entre os resultados obtidos nos dois estudos.

Estudo 1 (2001)

- Desempenho escolar: Não atendeu a pedido de desenho livre, fez traçados simples acompanhando modelos. Nomeou todas as cores. Não examinou o material para leitura (não olhou, não parou sentado, "chutou" respostas). Diferenciou desenho de escrita, fazendo traçados como rabiscos. Sozinho, contou até 2, e, com indicação do material a ser contado, até 5.

- Conversas temáticas: Participou de uma conversa, com o tema escola, em que respondeu a perguntas, dizendo o nome de uma colega e o da professora, e sobre o que comia na escola. Suas respostas foram coerentes, sem acrescentar detalhes ao indagado.

Estudo 2(2002)

- Desempenho escolar

$\mathrm{Na}$ avaliação, realizada em agosto, nomeou cores, não identificou letras ou palavras (em geral, dando pouca atenção ao 
material apresentado), escreveu seu nome em letras móveis com ajuda para localização de algumas letras. Escreveu outras palavras com traçados como bolinhas, segmentando a fala, à medida que fazia os traçados. Recitou a seqüência de contagem até 7; não fez contagens com correspondência, resistiu a orientações para tocar, um a um, os objetos a serem contados. Em novembro, começou a escrever seu nome em letras de forma, sem ajuda.

\section{Conversas temáticas}

Em geral, respondeu ao que foi perguntado, sem muitos detalhes. Foi influenciado por colegas, participando de assuntos iniciados por eles.

- Avaliação assistida individual-contagem:No início, recitou seqüência corretamente (até 9) e fez erros nas correspondências. Após orientação para deslocar bastante cada cubo contado, começou a ter predomínio de acertos nas correspondências (entre número falado e objeto contado). Nas subtrações (desde 9, com redução sucessiva de 1 a 1 cubo), recontou a cada retirada, acertando de imediato no caso de 1 e 2 .

\section{- "Espertezas"}

Dentre os exemplos observados, foram destacados os seguintes:

Sua mãe contou que tem um neto pequeno e que Inácio fala para ele "pedir a bênção para o tio".(05/08)

Quando Gisela se lembrou do Quindim (rinoceronte do sítio), Inácio se lembrou de outros personagens do Sítio do Pica-Pau Amarelo.(12/08)

Ao ver uma cadeira no corredor do serviço em que ocorre o projeto (cadeira de braços, com apoio para a cabeça, para exame fonoaudiológico), falou que era igual à de cabeleireiro.(14/10)

\section{Considerações sobre os resultados de Inácio}

Seu desempenho em avaliações formais foi baixo nos 2 anos, com destaque para a falta de atenção e concentração nas tarefas propostas. Nas conversas temáticas, respondeu às questões, embora sem muitos detalhes. Muitas vezes, não chegava a olhar para o material apresentado, "chutando" respostas. Na avaliação individual de contagem, mostrou disponibilidade para aprender, começando a fazer correspondências. Ao longo do segundo semestre de 2002, teve novas aquisições (início da escrita de seu nome) e mostrou, em situações informais, evidências de atenção, memória, compreensão e estabelecimento de relações entre fatos.

Inácio começou a freqüentar os grupos do projeto em outubro de 2001. Inicialmente, e na maior parte de 2002, tinha pouco tempo de atenção e pouco interesse por tarefas escolares (Ex.: identificação de figuras, contagem). Muitas vezes, saía do lugar no período de atividades à mesa, muitas vezes se colocando em baixo da mesa, e provocando os colegas. Sua mãe era bastante tolerante, fazendo comentários indicando que considerava normal ele não ter interesse por atividades escolares. Gradualmente, ao longo do ano, passou a apresentar algumas aquisições, conforme descrito nos resultados das avaliações.

\section{Resultados de Daniel}

- Desempenho escolar: Não acertou nomes de cores, fez desenhos com traçados fortes, colorindo toda a página, com várias cores de giz de cera. Nomeou um desenho ao entregá-lo, dizendo ser caminhão (Lúcio estava desenhando caminhão), não reconhecível. Não identificou letras; ao ser solicitado a escrever, não diferenciou desenho de escrita. Contagem: alguns acertos com valores baixos ao recitar seqüência; ausência de correspondência, aceitando algumas orientações para iniciar contagem com correspondência; acertos ao identificar 1 e 2 objetos.

Conversas temáticas: Indagado sobre atividades preferidas, respondeu descrevendo várias atividades do cotidiano (Ex.: tomar banho, tomar café). Quando o tema foi escola, enumerou várias atividades da escola, algumas com detalhes (Ex.: seqüência de rotinas da refeição). Algumas vezes se ateve ao tema, outras não, e, nesses casos, abordou assuntos de modo fantasioso e nem sempre compreensível.

\section{Avaliação assistida individual}

Cores: Começou errando. Ao longo das interações com o adulto, com indicações diretas (nome da cor), orientações para emparelhamento e com pistas (Ex.: começo do nome), passou a acertar na maioria das vezes (principalmente amarelo e vermelho).

Contagem: Aceitou orientações, passou a recitar corretamente a seqüência numérica até 10 , sem efetuar correspondências com independência.

"Espertezas": A partir de outubro, Daniel passou a mostrar um aumento de agitação, inclusive com agressões leves a colegas, que levaram à proposta de atendimento individual, até o final do semestre. Dentre as observações realizadas no grupo, destacamse as seguintes:

Sugeriu que se fizesse "chocolatão", colocando leite moça e chocolate.(12/08)

Disse que tem "catarata congênita" (correto).(19/08)

Falou "Meu nome é Enéas 5656", na época da campanha eleitoral $(23 / 09)$

Das sessões individuais do final de 2002, destacam-se as seguintes observações:

Ao pegar o brinquedo ônibus com pinos, nomeou cores dos pinos (com ajuda, rapidamente passou a acertar) e espontaneamente, agrupou os de mesma cor e contou, usando estratégia de separar cada objeto contado, conforme indicado em sessão anterior. (18/11)

Ao brincar pela segunda vez puxando caminhão basculante carregado com frutas, foi mais cuidadoso nas manobras, evitando colisões e quedas. Participou de brincadeiras de faz-de-conta envolvendo a venda das frutas e a utilização de um elevador imaginário para erguer e baixar o caminhão "para trocar pneu". $(2 / 12)$ 


\section{Considerações sobre os resultados de Daniel}

Daniel teve resultados muito baixos nas avaliações formais, sendo a única criança a não dominar nomeação de cores. Mostrou um alto grau de atividade agitada e alguns episódios de agressão, o que levou à suspensão temporária de sua participação no grupo. Seus relatos traziam fatos reais, misturados a fantasias, nem sempre compreensíveis. Nas situações de avaliação assistida individual, apreendeu várias das noções apresentadas. As observações informais indicaram exemplos de memorização, de compreensão de propostas (Ex.: faz-de-conta com caminhão) e de aprendizagem, em situações em que se conseguia um mínimo de atenção concentrada de sua parte.

\section{Resultados de Edith}

- Desempenho escolar: Fez desenhos parcialmente reconhecíveis, mantendo o tema ao longo da tarefa. Sua escrita se compôs de traçados diferentes dos desenhos, com traços iguais (geralmente invertido) ou parecidos com letras, feitos em linha, da direita para a esquerda. Recitou a seqüência de contagem até 4 , sem correspondência.

Conversas temáticas: Para todos os assuntos, respondeu ao que foi perguntado, mantendo-se no tema, descrevendo situações com vários detalhes. Continuou assuntos iniciados por Karina.

- Avaliação assistida individual: Leitura: Identificou a letra E, seu crachá e o crachá de Karina. Esteve concentrada durante toda a atividade.

- Contagem: Com orientação para deslocar bastante cada objeto contado, facilitando a correspondência termo a termo, passou a ter predomínio de acertos, na contagem até 8 .

— "Esperteras": Entre os exemplos observados, figuram os seguintes:

Trouxe lápis de cor, que ela mesma tinha marcado em casa, colocando pequenas etiquetas e com o "nome" (traçados sinuosos) em cada uma. No fim da atividade, havia um lápis da instituição misturado com os seus, e, na hora de guardar, Edith o identificou e o colocou de volta na caixa.(20/08).

Fez várias letras na lousa: I,E,D,R,N,A,P (invertidas) e A,P,T,D (na posição correta), pela primeira vez.(22/10)

Fez um desenho de figura humana reconhecível.(22/10)

\section{Considerações sobre os resultados de Edith}

Com baixo desempenho nas avaliações formais, Edith mostrou, em situações de avaliação assistida individual, exemplos de aprendizagem, no que se refere a leitura e contagem. Nas situações de conversa temática, mostrou capacidade de responder a perguntas sobre seu cotidiano de modo bastante completo. As observações de situações informais indicaram interesse por atividades envolvendo desenho e escrita, com graduais aquisições. Observou-se, em todas as situações, atenção concentrada nas tarefas propostas.
Edith era muito quieta, demorando ou resistindo a participar de várias das atividades propostas. Inicialmente, falava muito pouco, com voz quase inaudível. Ao longo de 2002, passou a falar mais, com mais clareza, e a defender seus espaços, principalmente junto a Karina, que tinha tendência de ser dominadora na organização das tarefas e no responder às solicitações.

\section{Resultados de Karina}

- Desempenho escolar: Fez desenhos parcialmente reconhecíveis (com características gerais de humanóides, sem detalhes que permitissem diferenciar seu auto-retrato do desenho de um panda, quando traçou os dois no mesmo dia). Identificou algumas letras e algumas palavras, estas por reconhecimento global. "Escreveu" seu nome com algumas letras reconhecíveis, e outras palavras com traços semelhantes a letras, algumas vezes correspondendografismos a sons (soletrando). Contagem: Recitou a seqüência até 6 , algumas vezes fazendo a correspondência correta. Identificou os numerais 1 e 3.

- Conversas temáticas: Para todos os temas, respondeu com relatos coerentes e detalhados ao que foi perguntado. Ao continuar assuntos trazidos pela colega Edith, apresentou novas contribuições ao mesmo.

Avaliação assistida individual - contagem: Com pequenas correções, contou corretamente até 10. Nas subtrações de 1 , sempre recomeçava a contagem do conjunto remanescente. Reconheceu alguns dos numerais (1 a 4), referindo-se ao 4 como "o da cadeirinha". Ao ser apresentada à tarefa com numerais, disse que "odiava números".

— "Espertezas": Foram destacados os seguintes exemplos:

Quando Karina foi colocar folhas sulfite dentro do envelope, disse que era mais fácil colocar o envelope de pé, fez isso e as folhas deslizaram para dentro (Antes, recusava-se a executar tarefas que exigissem movimentos finos).(06/08)

Ao ver aprimoranda de óculos, observou que antes ela não usava óculos. $(13 / 08)$

Edith perguntou quantos lápis havia na caixa, C. disse 12, Karina disse: "É a mesma quantidade que eu levo na escola". (20/08)

Em atividade de desenho, disse que "azul com amarelo dá verdeclaro" (provavelmente lembrando o que aprendeu na escola).(08/ 10)

Estava falando de um "shopping" recém inaugurado, e disse que lá "muda de piso" (o shopping tem várias alas, cada uma com um tipo de piso).(22/10)

Karina trouxe um ratinho de corda no atendimento e, na hora de mostrar como acionar, fez movimento de pinça para dar corda no brinquedo (o que normalmente se recusava a fazer, inclusive para pegar o lápis).(04/11)

\section{Considerações sobre os resultados de Karina}

Como as demais crianças, Karina teve baixos resultados nas avaliações formais, situação agravada por sua idade (12 anos). 
Por outro lado, seus relatos continuavam bastante ricos, com bom desenvolvimento a partir dos temas propostos, de modo coerente e compreensível. $\mathrm{Na}$ avaliação assistida individual, mostrou alguma aprendizagem, respondendo às orientações dadas, embora seu desempenho em tarefas escolares não estivesse mostrando progressos significativos. As observações informais indicaram várias capacidades: memorização, observação do ambiente, solução de pequenos problemas (colocar folha em envelope, coisa que ela se recusava a fazer), estabelecimento de relações entre eventos e ocorrência de uma habilidade (Ex.: movimento em pinça) em área em que ela recusava orientação.

Karina participava do projeto desde setembro de 1999. Nos primeiros anos, mostrava muita agressividade em relação aos colegas (tapas e palavrões) e recusava, fortemente, atividades escolares. Já tinha boa capacidade de fazer relatos de fatos acontecidos. Essa agressividade se reduziu, mas persistiu uma auto-avaliação negativa, refletida em constantes comentários do tipo: “Sou burra" ou 'Sou doida, mesmo!'. A partir de 2001, demonstrou capacidade cognitiva em duas situações adicionais: seu desenho começou a ser reconhecível e, na brincadeira fazde-conta, mostrou capacidade de assumir papéis (Ex.: "polícia" e "ladrão"). Sua famillia tinha grandes expectativas em relação à aprendizagem de leitura e escrita, inclusive realizando, por conta própria, atividades nessa direção, o que parecia aumentar a aversão de Karina pelas mesmas. Por outro lado, não havia a valorização de outras aquisições por parte da familia (Ex.: aprimoramento do desenho). Ao longo de muitas interações com Karina e com a família, surgiu a hipótese de que suas dificuldades não se deviam, unicamente, a uma limitação por dano cerebral, mas, também, à aversividade que as situações de ensino haviam adquirido. Um indício que pareceu confirmar essa hipótese foi a observação de seu uso do movimento de pinça, em situação não solicitada, quando, normalmente, resistia fortemente a qualquer tentativa de instrução sobre como segurar o lápis (habitualmente, Karina colocava o lápis entre os dedos indicador e médio e aproximava o polegar, sem fazer a pinça).

\section{Discussão e Conclusão}

É possível identificar habilidades, em crianças com reconhecidas dificuldades de aprendizagem? Consideramos que, em todos os casos apresentados, foi possível identificar possibilidades e capacidades por meio dos diferentes procedimentos adotados. Consideramos, também, que essa busca cuidadosa por habilidades foi mais proveitosa que a realização de inventários padronizados para o mapeamento das áreas de dificuldade dessas crianças, por indicar, justamente, exemplos de aquisição.

Quais seriam as melhores estratégias para identificar habilidades, quando a falta de habilidades parece ser o padrão? Os testes padronizados fornecem um valor numérico, desacompanhado de informações sobre capacidades em desenvolvimento. Permitem uma comparação com a população de mesma faixa etária, embora com os vieses já explicitados anteriormente.

A avaliação assistida traz indicações sobre capacidades da criança, bem como sobre seus focos de resistência e dificuldade. Entretanto, quanto mais padronizada, menos dados positivos fornece sobre crianças como as estudadas no presente trabalho, conforme constatado em tentativas anteriores de utilização dessa modalidade. E, mesmo em sua modalidade clínica, tem limites: trata-se, sempre, de uma tarefa específica, a ser apresentada em um momento determinado. Dessa forma, nem sempre se conseguem todas as informações sobre os "pontos fortes" de aquisição dessas crianças.

A alternativa proposta no presente estudo é complementar os dados obtidos por meio da avaliação padronizada e assistida, com a observação atenta da criança, em diferentes situações de interação, buscando-se a identificação de exemplos de “espertezas". Dessa forma, foi possível, por exemplo, identificar várias capacidades em Gisela: ela aplicou, no contexto correto, conhecimentos anteriormente obtidos sobre histórias infantis, canções e atividades do dia-a-dia. Estabeleceu relações (a galinha criar pintinhos e sua mãe criá-la) e se lembrou de colegas que tinham deixado de freqüentar o grupo. As "espertezas" relatadas para as outras crianças trazem, também, exemplos de habilidades de observação, de estabelecimento de analogias e o conhecimento de papéis e fatos do cotidiano.

Por que essas crianças parecem resistir a procedimentos de avaliação, mesmo os de avaliação assistida, supostamente muito mais "amigáveis"? Uma situação semelhante foi observada em um estudo sobre a avaliação da acuidade visual (Batista \& Rassi, 2001), que visava testar um procedimento desenvolvido pela oftalmologista Lindstedt (1997a, 1997b) para crianças com dificuldade de colaboração ou compreensão. A metodologia proposta envolve a identificação de pares de figuras conhecidas, que vão sendo apresentadas em cartões individuais progressivamente menores (Ex.: garfo/colher, tesoura/óculos). Para iniciar o procedimento, sugere-se a apresentação, para a criança, de objetos reais, a serem manuseados livremente e pareados com suas respectivas figuras. Trata-se, assim, de uma situação mais "amigável" que a apresentação de tabelas com as figuras-padrão apresentadas em linhas. No estudo referido, a avaliação foi realizada pela segunda autora, uma ortoptista com larga experiência com crianças. Nessa situação, foi possível obter a acuidade visual da maioria das crianças submetidas ao procedimento, uma delas em uma segunda oportunidade de aplicação. Verificou-se que, entre as dificuldades constatadas, estava a de manter o interesse pelo período necessário para a obtenção da acuidade. Algumas crianças mostravam sinais crescentes de impaciência e desconforto, outras pareciam ter dificuldade de responder à tarefa de pareamento. Acrescente-se o fato de que, nesse tipo de avaliação, a tarefa vai ficando progressivamente mais difícil (as figuras são cada vez menores).

Entre os aspectos que se aplicam à atual situação, inclui-se a dificuldade, muito presente nessas crianças, de manter a atenção 
por período prolongado para tarefas propostas por um adulto. Essas tarefas (contar, identificar formas e palavras, estabelecer relações entre objetos) parecem trazer uma resistência, o que é menos observado nas crianças com bom desempenho. É possível que isso se deva à semelhança dessas tarefas com as atividades escolares nas quais essas crianças têm dificuldade, e que geram, muito provavelmente, sensações de fracasso e incompetência. Parece que essas tarefas, ou geram desconforto, ou não fazem sentido para essas crianças. Essas resistências são praticamente inexistentes nas situações de conversa e brincadeira mais livre, ou em atividades e jogos menos semelhantes às atividades acadêmicas formais. E foi justamente nessas situações que as “espertezas" foram constatadas. De fato, podemos afirmar que as crianças sempre têm interesse por algumas atividades e objetos, só que este raramente coincide com as sugeridas pelo avaliador. E, na maioria dos casos, um bom rapport não é suficiente para promover esse envolvimento. A alternativa é buscar atividades de interesse das crianças, de preferência em diferentes modalidades, e observar suas capacidades nas situações em que elas estejam mais à vontade.

A idéia da importância da avaliação em diferentes situações é corroborada por um fato freqüentemente observado nessas crianças: uma certa imprevisibilidade quanto ao momento em que vão demonstrar suas habilidades. Por exemplo: no início das atividades do projeto em 2003, mães e algumas crianças compareceram para uma reunião. Edith, abordada pela pesquisadora que ela conhece há vários anos, ficou calada, não respondendo a nenhuma pergunta. Já Gisela conversou com desembaraço, recordando-se de histórias contadas no ano anterior, sendo que essas atividades, no momento em que ocorreram, não ensejaram manifestações tão claras do interesse e compreensão de Gisela.

Parece que as habilidades em fase de aquisição são, também, dependentes de contextos favoráveis, nem sempre coincidentes com os das situações de avaliação. Permitimo-nos citar um exemplo, relatado para a primeira autora por uma pessoa de idade, que sempre se caracterizou por extrema timidez. O fato ocorreu na década de 1920, quando essa senhora tinha 8 anos. Ela teria um exame de Trabalhos Manuais em que seria exigida a confecção de um vestido de papel. Sem contar nada para ninguém, ela conseguiu fazer o trabalho em casa e levá-lo, já pronto, para a escola, o que, em princípio, não seria permitido. Foi muito elogiada, tendo o trabalho sido mostrado para várias professoras da escola. Ao relatar o fato, ela comentou que não teria conseguido executar a mesma tarefa em casse, sob os olhares severos da professora e dos colegas.

A preocupação explicitada no presente trabalho é, nos termos de Vygotksy (1989), desenvolver estratégias para identificar o nível de desenvolvimento potencial naquelas crianças em que isso é mais difícil. Trata-se de uma questão de relevância teórica e prática: teórica, pois discute os indicadores de aprendizagem e desenvolvimento; prática, pois tem relação com diagnóstico, prognóstico e decisões educacionais.

\section{Referências}

Batista, C. G. \& Enumo, S. R. F. (2000). Desenvolvimento humano e impedimentos de origem orgânica: O caso da deficiência visual. Em H. A. Novo \& M. C. S. Menandro (Orgs.), Olhares diversos: Estudando o desenvolvimento humano (pp.157-174). Vitória, ES: UFES, Programa de Pós-graduação em Psicologia, Capes/Proin.

Batista, C. G. \& Rassi, M. M. O. (2001). Assessment of visual acuity in toddlers and children with develomental delays: The joint contribution of ophthalmology, orthoptics and psychology. Visual Impairment Research, 3, 17-30.

Bock, A. M. B., Furtado, O. \& Teixeira, M. L. T. (2001). Psicologias: Uma introdução ao estudo depsicologia (13 ed.). São Paulo: Saraiva.

Colenbrander, A. (1999). Guide for the evaluation of visual impairment of the International Society for L ow vision Research and Rehabilitation (ISLRR). San Francisco: Pacifc Vision.

Coll, C. \& Onrubia, J. (1996). Inteligência, aptidões para a aprendizagem e rendimento escolar. Em C. Coll, J. Palácios \& A. Marchesi (Orgs.), Desenvolvimento psicológico e educação (Vol. 2, pp. 141-153, A. M. Alves, Trad.) Porto Alegre: Artes Médicas. (Original publicado em 1939)

Enumo, S. R. F.\& Batista, C. G. (2000). Evaluating cognitive abilities of visually impaired children. Em C. Stuen, A. Arditi, A. Horowitz, M. A. Lang, B. Rosenthal \& K. R. Seidman (Orgs.), Vision rehabilitation: Assessment, interventions and outcomes (pp. 379381). EUA: Sweets \& Zeitlinger.

Lemgruber, V. \& Paine, P. A. (1981). Adaptação brasileira da escala verbal do WISC. Arquivos Brasileiros de Psicologia, 33, 32-56.

Lindstedt, E. (1997a). BUST-Examen de visión para niños. Solna, Switzerland: SIH Läromedel.

Lindstedt, E. (1997b). How well does a child see? A guide on vision and vision assessment in children. Switzerland: Kristinehamns Kommuns Reproavdelining.

Linhares, M. B. M. (1995). Avaliação assistida: Fundamentos, definição, características e implicações para a avaliação psicológica. Psicologia: Teoria e Pesquisa, 11, 23-31.

Linhares, M. B. M. (1998). Avaliação assistida de crianças com queixa de dificuldade de aprendizagem: Indicadores de eficiência e transferência de aprendizagem em situação de resolução de problema. Em A. W.Zuardi, E. M. Marturano, M. A. C. Figueiredo \& S. R. Loureiro (Orgs.), Estudos em saúde mental. Ribeirão Preto: Comissão de Pós Graduação em Saúde Mental da FMRP/USP.

Santa Maria, M. R. \& Linhares, M. B. M. (1999). Avaliação cognitiva assistida de crianças com indicações de dificuldades de aprendizagem escolar e deficiência mental leve. Psicologia: Reflexão e Crítica, 12, 395-417.

Veitzman, S. (2000). Visão subnormal. Rio de Janeiro: Cultura Médica.

Vygotsky, L. S. (1989). A formação social da mente São Paulo: Martins Fontes.

Sobre as autoras

Cecília Guarnieri Batista é Psicóloga, Mestre e Doutora em Psicologia pela Universidade de São Paulo. É Professora da Faculdade de Ciências Médicas e do Centro de Ensino e Pesquisa em Reabilitação da Universidade Estadual de Campinas.

Maria Eduarda Silva Leme é Psicóloga, Mestre em Educação pela Universidade Estadual de Campinas e Especialista pelo Centro de Ensino e Pesquisa em Reabilitação da Universidade Estadual de Campinas.

Letícia Enya Horino é aluna de graduação na Pontifícia Universidade Católica de Campinas.

$1^{a}$ Revisão: $19 / 08 / 2003$ Aceite Final: 29/10/2003 
Anexo A

Detalhamento do procedimento de análise dos dados de Edith, no Estudo 1.

\section{- Desempenho escolar:}

Identificação de cores: Foram apresentados cartões com borrões nas cores vermelho, verde, amarelo, branco, azul e preto, que também tinham materiais texturizados nas mesmas cores, para nomeação das cores, com os cartões deslocados sucessivamente entre os membros do grupo.

\begin{tabular}{llcc}
\hline & resumo das observações & categoria & contagem \\
\hline vermelho & disse corretamente a cor & AS & 6AS \\
verde & disse corretamente a cor & AS & \\
amarelo & disse corretamente a cor & AS & \\
branco & disse corretamente a cor & AS & \\
azul & disse corretamente a cor & AS & \\
preto & disse corretamente a cor & AS & \\
\hline
\end{tabular}

Síntese: nomeou todas as cores.

Leitura: Foram apresentados, em rodízio, os crachás com nomes das crianças do grupo (aqui exemplificados pelos nomes fictícios).

\begin{tabular}{llcc}
\hline & resumo das observações & categoria & contagem \\
\hline crachás & crachá de Edith- identificou corretamente & RS & 2RS \\
& crachá de Beatriz- "Dago", Cecilia, adulto & ES & 1ES \\
& coordenador (C.), falou & & 1EP \\
& crachá de Dago- C. falou a letra inicial, E. não respondeu & EP & \\
& crachá de Edith- olhou o crachá de ponta cabeça e o identificou & RS & 1 AS \\
letras & E- "Edith" & OT & AS \\
& B- nomeou corretamente, não respondeu quando C. & & $1 \mathrm{ES}$ \\
& perguntou o que se escreve com a letra & ES & 1 OT \\
& D- Dago falou "A", Edith repetiu "A", C. falou "D" & NS & (outros) \\
\hline
\end{tabular}

Categorias: RS- reconhecimento sem interferência por indícios parciais (ex: configuração da palavra); ES- erro sem interferência; EP- erro após pistas; OT- outros; AS- resposta correta sem interferência; NS- não resposta sem interferência.

Síntese: Identificou seu nome, provavelmente por indícios de configuração, e acertou a letra B.

Escrita: Foi entregue uma folha de sulfite branca, e foi solicitado que Edith escrevesse seu nome. Dependendo do desempenho, era pedido que a criança escrevesse também uma outra palavra, escolhida pela criança.

\begin{tabular}{llcc}
\hline & resumo & categoria & contagem \\
\hline nome & Disse que ia escrever "Edith". Girou a folha em várias & TS & 1TS \\
& direções, fez alguns riscos, alguns eram um círculo com uma & & \\
& reta na vertical embaixo. Enquanto desenhava, identificou & & \\
"guarda-chuva" e "uma casa". Quando C. foi recolher, falou & & \\
que faltava o nome, fez alguns traçados parecidos com a letra & & \\
"N", e disse ser a letra "B”, escreveu da direita para a esquerda & & - \\
outra palavra & não foi solicitada a escrever outra palavra & - & \\
\hline
\end{tabular}
Síntese: Distinguiu desenho de escrita. Usou traços parecidos com a letra N, dizendo ser B. Escreveu da direita para a esquerda.

(Categoria TS: traçado sem interferência.) 
Contagem: Foram apresentados cartões com número variado de bolinhas (pares Proepre). Nesse material, a posição das bolinhas varia nos pares, de modo a incentivar a contagem "real" e dificultar a memorização da configuração.

\begin{tabular}{clcc}
\hline pares Proepre & resumo & categoria & contagem \\
\hline 3 & contou 1,2,3,7; C. a corrigiu. & ES & 4ES \\
& falou a seqüência numérica errada e repetiu as & ES & \\
& bolinhas na contagem, C. contou & & \\
& olhando para o cartão, falou números, C. contou & ES \\
& apontando para as bolinhas falou números na ordem errada & ES & \\
\hline
\end{tabular}

E. não recitou seqüência numérica corretamente e não fez correspondência entre número e bolinha.

Desempenho escolar - síntese: No que se refere ao desempenho escolar, avaliado em situação de grupo, verificase que Edith nomeou cores, reconheceu seu nome, estava iniciando a identificação de letras, distinguia desenho de escrita e não fazia contagens.

Embora não tenha feito a tarefa de desenho para avaliação, nas tarefas normais do grupo seu desenho não era reconhecível.

\section{- Conversas temáticas:}

Em geral, Edith falava muito baixo, de modo quase inaudível. Demorava para responder, sendo, em geral, "atropelada" pelos colegas. Um resumo das conversas de que participou é apresentado a seguir. Nessas conversas, o adulto coordenador apresentava o tema, e fazia várias perguntas específicas (ex: nome do pai, nome da escola, etc).

Tema Resumo (R) e comentário (C)

Família

R: Disse o nome da mãe, do pai e dos irmãos. Contou a idade dos irmãos. Contou que "estudava no prezinho" e que morava com sua mãe, avó e avô.

C: Trouxe várias informações, detalhadas, apresentadas de modo compreensível. Respondeu a perguntas específicas (não desenvolveu o tema extensamente).

Vinda ao R: Confirmou que vem de perua (monossílabos), respondeu que é sua mãe que vem com ela. Não serviço em respondeu o nome de sua cidade. Quando a conversa foi para outros temas, respondeu sobre o que se localiza nome de sua escola (incompleto) e o nome da professora. Gilberto falou em futura festa de o projeto aniversário, C. lembrou que era o dia do aniversário de Edith e perguntou quantos anos ela estava fazendo. Edith respondeu corretamente: sete anos.

C: Respondeu, com poucas palavras, à maioria das perguntas (não a todas). Não trouxe detalhes, não se estendeu sobre o tema proposto.

Conversas temáticas - síntese: Edith apresentava poucas iniciativas durante conversas, não se estendendo sobre temas propostos. Quando indagada diretamente, respondia à maioria das perguntas. 